\title{
On Young's modulus of multi-walled carbon nanotubes
}

\author{
K T KASHYAP* and R G PATIL \\ Department of Mechanical Engineering, People Education Society Institute of Technology, 100 Feet Ring Road, \\ Bangalore 560 085, India
}

MS received 9 April 2007; revised 22 January 2008

\begin{abstract}
Carbon nanotubes (CNTs) were discovered by Iijima in 1991 as the fourth form of carbon. Carbon nanotubes are the ultimate carbon fibres because of their high Young's modulus of $\approx 1$ TPa which is very useful for load transfer in nanocomposites. In the present work, CNT/Al nanocomposites were fabricated by the powder metallurgy technique and after extrusion of the nanocomposites bright field transmission electron microscopic (TEM) studies were carried out. From the TEM images so obtained, a novel method of ascertaining the Young's modulus of multi-walled carbon nanotubes is worked out in the present paper which turns out to be 0.9 TPa which is consistent with the experimental results.
\end{abstract}

Keywords. Multi-walled carbon nanotubes; CNT/Al nanocomposites; Young's modulus; TEM.

\section{Introduction}

Carbon nanotubes which were discovered by Iijima (1991) have unique electronic, physical and mechanical properties (Harris 2004). The CNTs can be regarded as the ultimate form of carbon fibre with a Young's modulus of 1.28 TPa as shown by Lieber et al (Harris 2004) where they obtained lateral force $(F)$ and displacement $(d)$ curves for multiwalled CNTs in an atomic force microscope (AFM). From the slope of the lateral force-displacement curves, the Young's modulus of $1.28 \mathrm{TPa}$ was obtained. Treacy et al (1998) by using TEM obtained a modulus of 410 $2000 \mathrm{GPa}$ with an average of $1800 \mathrm{GPa}$.

Several workers, notably Overney et al (1993), have carried out theoretical analysis of the Young's modulus of CNTs by using Keating potential with a modulus prediction of 1500-5000 GPa. Hernandez et al (1998) found on an average, $1240 \mathrm{GPa}$ by tight binding calculations whereas Lu (1997) found a value of $970 \mathrm{GPa}$ based on theoretical tight binding calculations. The theoretical modulus of the graphene sheet is supposed to be $1060 \mathrm{GPa}$ (Harris 2004). The reason why multi-walled nanotubes have a modulus $>1060 \mathrm{GPa}$ (that of graphene sheet) is currently not understood. However, in the present paper, a novel analysis based on transmission electron microscopy of carbon nanotube/aluminum nanocomposites is given to calculate approximately the Young's modulus of multi-walled carbon nanotubes.

\section{Experimental}

Multi-walled carbon nanotubes (MWCNTs) were synthesized by arc discharge technique with $20 \mathrm{~V}$ d.c. and 100

*Author for correspondence (ktkashyap@yahoo.com) amps current. The CNT/Al nanocomposites were synthesized by powder metallurgy technique. MWCNTs and commercial purity Al powder were blended, ball milled, compacted and sintered and hot extruded at $560^{\circ} \mathrm{C}$ to produce $5 \mathrm{~mm}$ rods. The nanocomposites were characterized for properties as described by George et al (2005). These were sliced and polished in a double jet electro polisher with perchloric acid and ethanol as electrolyte at $11 \mathrm{~V}$ d.c., observed on a $100 \mathrm{kV}$ electron microscope and the bright field images were photographed.

\section{Results, discussion and calculations}

Figures 1 and 2 show the bright field TEM images of CNT/ Al composite with MWCNTs bent on sub-grain boundaries. It is clearly observed that sub-grains have formed in the hot extruded CNT/Al nanocomposite due to the high stacking fault energy of aluminum, due to which crossslip, glide and climb of dislocations takes place from which low angle grain boundaries form. The MWCNTs seem to pin sub-grain boundaries and due to the pressure and curvature of sub-grain boundaries, the MWCNTs are bent. This bending of MWCNTs provides us a method and offers a unique analysis for the Young's modulus of the MWCNTs. One can use the classical Gibbs-Thomson equation to calculate the force acting on the MWCNT and knowing the deflection of the MWCNT which is the radius of curvature of the sub-grain boundary and using the analysis for simply supported beam, uniformly distributed load over the MWCNT, the Young's modulus can be calculated.

From the Gibbs-Thomson equation (Doherty and Cantor 1997) 


$$
\Delta P=\frac{2 \gamma}{R},
$$

where $\Delta P$ is the pressure difference across sub-grains with intervening carbon nanotube which is bent at the subgrain boundary, $\gamma$ the surface energy of the low angle grain boundary which is assumed to be $0.5 \mathrm{~J} / \mathrm{m}^{2}$ (ReedHill and Abbaschian 1991) and $R$ the radius of curvature of the sub-grain or cell pinned by MWCNTs and which is assumed to be $2 \mathrm{~nm}$ from figures $1-4$.

The above Gibbs-Thomson equation describes the pressure exerted by a grain boundary due to its curvature. Here this pressure is exerted on the carbon nanotube which pins the sub-grain boundary. It is to be noted that the above equation is valid for any type of curved interface in solids, especially high and low angle grain boundaries.

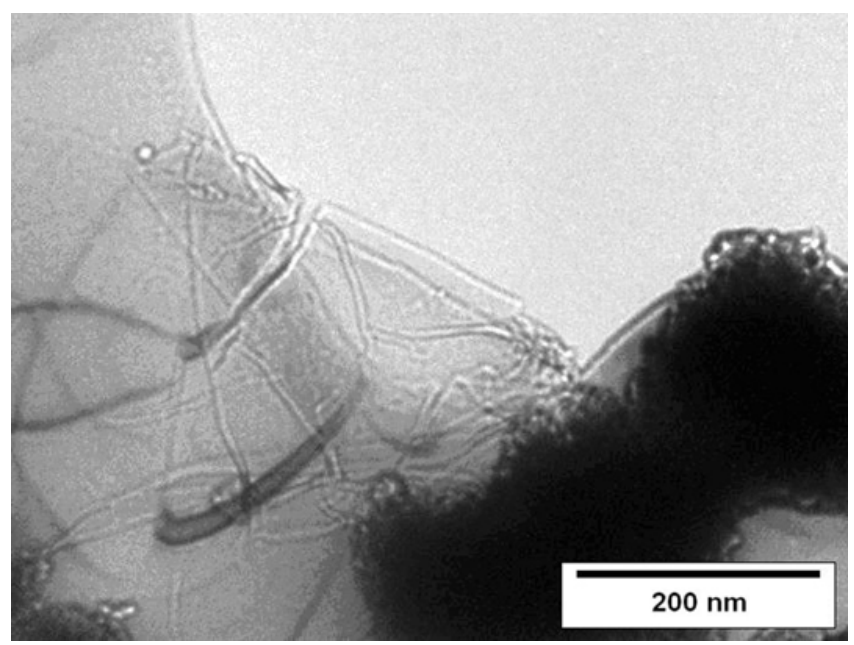

Figure 1. Bright field TEM image of CNT-Al composite showing deflection of nanotubes at sub-grain boundaries.

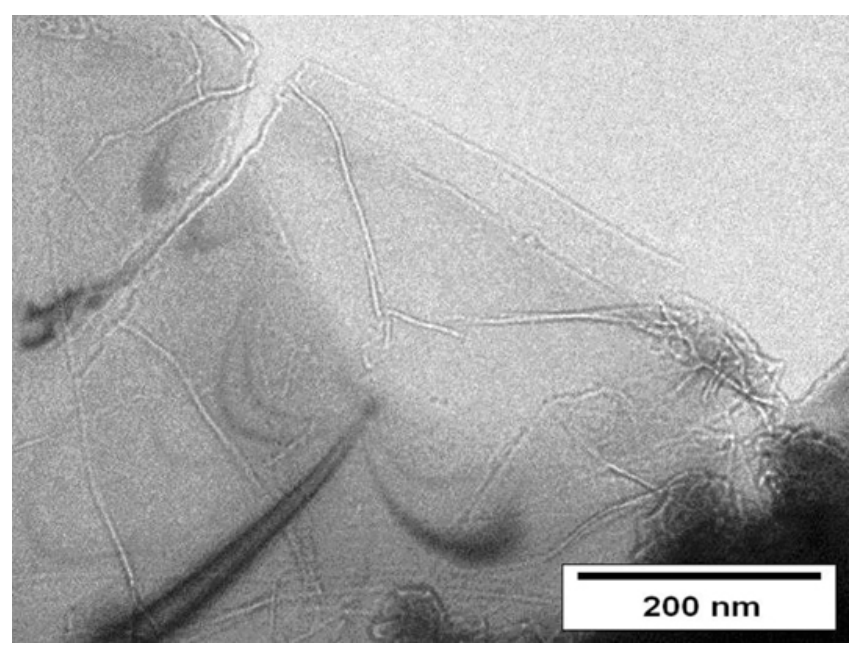

Figure 2. Bright field TEM image of CNT-Al composite showing deflection of nanotubes at sub-grain boundaries.
Analysis I: Simply supported beam:

$$
\Delta P=\frac{2 \times 0.5\left(\mathrm{~J} / \mathrm{m}^{2}\right)}{2 \mu \mathrm{m}}=10^{6} \mathrm{~N} / \mathrm{m}^{2} .
$$

Total force due to curvature of the sub-grain boundary acting on the surface of a MWCNT is

$$
\Delta P(2 \pi r L)=F,
$$

where $r$ is the outer radius of MWCNT in $\mathrm{nm}$ and $L$ the length of MWCNT in $\mu \mathrm{m}$.

$$
F=10^{6} 2 \pi(50 \mathrm{~nm})(1 \mu \mathrm{m})=314 \times 10^{-9} \text { Newton. }
$$

This force is assumed to act at the centre of the MWCNT which is considered to be a simply supported beam. The standard equation for the deflection of a simply supported beam is

$$
\text { Maximum deflection, } y=\frac{F L^{3}}{48 E I} \text {, }
$$

where $F$ is the force in Newton, $L$ the length in metre, $E$ the Young's modulus and $I$ the moment of interia of the MWCNT.

$$
I=\frac{\pi\left(d_{0}^{4}-d_{\mathrm{i}}^{4}\right)}{64},
$$

where $d_{0}$ is the outer radius of the MWCNT and $d_{\mathrm{i}}$ the inside radius of the MWCNT, $d_{0}=50 \mathrm{~nm}$ and $d_{\mathrm{i}}=10 \mathrm{~nm}$.

$$
I=30.6150 \times 10^{-32} \mathrm{~m}^{4} .
$$

The length, $L$, of the CNT is taken to be $1 \mu \mathrm{m}$. Then

$$
\text { Young's modulus, } \begin{aligned}
E & =\frac{F L^{3}}{48 I Y_{\max }} \\
& =\frac{314 \times 10^{-9} \times\left(10^{-6}\right)^{3}}{48 \times 1 \times 10^{-6} \times 10^{-32}} \\
& =0.654 \mathrm{TPa} .
\end{aligned}
$$

This value of $E(0.654 \mathrm{TPa})$ is a bit lower than the value of $1.28 \mathrm{TPa}$ as obtained by Lieber (Harris 2004) using scanning probe microscopy.

Let us consider another analysis.

\section{Analysis II: Distributed load on a beam}

Here the MWCNT is considered with a distributed load since the pressure due to sub-grain curvature acts on the surface of the MWCNT.

Maximum deflection is

$$
Y_{\max }=\frac{5 w L^{4}}{384 E I}
$$

where $w$ is the force/unit length of the MWCNT, $E$ the Young's modulus, $I$ the moment of inertia of the MWCNT, $L$ the length of the MWCNT. 


$$
\begin{aligned}
& E=\frac{5 w L^{4}}{384 Y_{\max } I}, \\
& E=\frac{5 \times\left(314 \times 10^{-9} / 10^{-6}\right) \times 10^{-24}}{384 \times 10^{-6} \times 10^{-32}}, \\
& E=0.9 \mathrm{TPa} .
\end{aligned}
$$

This value of $0.9 \mathrm{TPa}$ for the Young's modulus of MWCNT is appreciably closer to the value of $1.28 \mathrm{TPa}$ obtained by Lieber (Harris 2004). In fact, the value of $1.28 \mathrm{TPa}$ was obtained by scanning probe microscopy from lateral force-displacement curves where the bending equation of a cantilever beam was used for maximum deflection. It is felt that the value obtained from TEM of $0.9 \mathrm{TPa}$ is reasonably an accurate prediction of the Young's modulus of the MWCNT.

\section{Conclusion}

A unique analysis by TEM allows the determination of the Young's modulus of the multi-walled carbon nanotubes to be 0.9 TPa by a simple analysis.

\section{Acknowledgements}

The authors wish to thank HOD, Mechanical Engineering Department, Principal and Management of PESIT, Bangalore, for encouragement and support.

\section{References}

Doherty R D and Cantor B 1997 Stability of microstructure in metallic systems (UK: Cambridge University Press)

George R, Kashyap K T, Rahul R and Yamdugni S 2005 Scr. Mater. 531159

Harris P J 2004 Carbon nanotubes and related structures (UK: Cambridge Univ. Press)

Hernandez E, Goze C, Bernier P and Rubio A 1998 Phys. Rev. Lett. 804502

Iijima S 1991 Nature 35456

Lu J P 1997 Phys. Rev. Lett. 791297

Overney G, Zhong W and Tomanek D 1993 Phys. D27 93

Reed-Hill Robert E and Abbaschian Reza 1991 Physical metallurgy principles (Thomson Publications) 3rd ed.

Treacy T, Ebbesen W and Gibson J M 1996 Nature 381678 